\title{
Proceeding
}

Supplementary Issue: Summer Conferences of Sports Science. First International Conference in Iraq on Sport for Peace, 4 April 2019. Baghdad Science Institute, Baghdad, Iraq.

\section{The mediating role of operational performance and internal integration of supply chain in the relationship between interplant coordination and external integration}

\author{
SUDAWAN SOMJAI ${ }^{1}$, LUEDECH GIRDWICHAI ${ }^{1}$, KITTISAK JERMSITTIPARSERT ${ }^{2,3}$ \\ ${ }^{1}$ Suan Sunandha Rajabhat University, Bangkok, Thailand \\ ${ }^{2}$ Department for Management of Science and Technology Development, Ton Duc Thang University, Ho Chi \\ Minh City, Vietnam \\ ${ }^{3}$ Faculty of Social Sciences and Humanities, Ton Duc Thang University, Ho Chi Minh City, Vietnam
}

\begin{abstract}
The focus of this research is on networked plant. The study has analysed the relation between supply chain integration, operational performance, and inter-plant coordination. The study has differentiated internal integration and inter-plant coordination. The extension of internal integration is internal-plant coordination as it involves eliminations of the functional silos in the internal integration are extended to span across the networked plants. This is distinct from the external integration as well. The external integration is based on individual firms and it does not deal in the firm's collaboration with external partners. The relation between supply chain integration and inter-plant coordination has been tested, which is the first contribution, as it was not done previously. The positive impact of internal integration created on the inter-plant coordination has been evidenced by this study. This research has tested a novel theoretical model about the role of external integration as a mediator on the relation of interplant coordination and performance. The previous studies have been complimented by this research through analysing the way in which operational performance is influenced by inter-plant coordination in a networked plant. The study has used SEM-PLS and data is collected from the sports manufacturing firms of Thailand. coordination through external integration. Keeping in view the relation of internal integration with the operational performance, external integration mediates the influence of interplant coordination on operational performance. Keywords: Supply chain; Coordination; Sports; Thailand.
\end{abstract}

Cite this article as:

Somjai, S., Girdwichai, L., \& Jermsittiparsert, K. (2019). The mediating role of operational performance and internal integration of supply chain in the relationship between interplant coordination and external integration. Journal of Human Sport and Exercise, 14(5proc), S2187-S2201. doi:https://doi.org/10.14198/jhse.2019.14.Proc5.38

Corresponding author. Department for Management of Science and Technology Development, Ton Duc Thang University, Ho Chi Minh City, Vietnam.

E-mail: kittisak.jermsittiparsert@tdtu.edu.vn

Supplementary Issue: Summer Conferences of Sports Science. First International Conference in Iraq on Sport for Peace, 4 April 2019. Baghdad Science Institute, Baghdad, Iraq.

JOURNAL OF HUMAN SPORT \& EXERCISE ISSN 1988-5202

(c) Faculty of Education. University of Alicante

doi:10.14198/jhse.2019.14.Proc5.38 


\section{INTRODUCTION}

The geographically dispersed plants of multinational corporations have been globalized during the last 20 years along with the movement of manufacturing system concepts to a network of manufacturing (Cheng et al, 2015; Olhager et al, 2015). A coordinated aggregation, which involves the location of intra-firm plants in different places for the perspective of covering dispersion of geography, is referred as network manufacturing. Moreover, it involves the independent coordination as compared with the traditional focus on separate sites of manufacturing (Cheng et al., 2015; Olhager et al., 2015). The purpose is to expand the boundaries of traditional manufacturing system to a multi-plant system from a single. However, it does not resolve the interfirm coordination. It is regarded as an internal network in which the financial control over all the plants is maintained (Cheng et al., 2015; Olhager et al., 2015). This type of firm, which is based on a manufacturing network, can learn greater about the products, customers, technology, and processes. This cannot be learned by a plant itself. This can result in achievement of flexibility and cost advantages through collaboration with the network plants. These benefits cannot be achieved by the plant itself. The issue of inter-plant collaboration can be experienced (Ibrahim et al, 2015). There is need for integration of the flow of material, skills management, development of product/processes and related knowledge with the network plants for achieving the benefits mentioned above (Cheng et al., 2015). The existing studies have not focused much on the issues of coordination. There is limited research on the relation of plant performance and In PLC in the network of manufacturing (Cheng et al., 2015; Erfurth \& Bendul, 2018). Moreover, for increasing collaboration with other plants, there is need for the plant to gain, share, and implicate information with the partners (internal and external) in order to align the business processes with the set objectives. The level with which the managers and supply chain partners collaborate strategically with the processes of inter and intra-organization. This is referred as $\mathrm{SCl}$ (supply chain integration). This concept has received great significance among the practitioners as well as academicians (Gelhard \& Von Delft, 2016). Further, the current studies on supply chain integration have barely focused on the plants in the manufacturing network. The studies have not focused on the integration between the internal functions with the customers and suppliers (Melander, 2018). The association between plant performance, SCl, and In PLC and SCI has not been analysed in previous studies.

\section{HYPOTHESIS DEVELOPMENT}

The coordination of inter-plant is its association with the operational Performance of Network Plant. The process of designing a manufacturing network is similar to the designing process of an operating system. There is need for making two types of decisions. The structural decisions for network designing are addressed by the decisions related with configuration. Moreover, the infrastructural relations between the plants are addressed through decisions related to coordination (Cheng et al, 2016). The question about creating integration of a network plant with other plants is referred as In PLC. This is done for achieving the strategic objective of a firm. The purpose of inter-plant coordination (In PLC) is to achieve the flow of physical and non-physical materials in an effective way between the plants of network (Erfurth \& Bendul, 2018). The configuration issue has been dealt by a number of researchers in the field of operations management. However, rare studies have given attention to the InPLC (Erfurth \& Bendul, 2018). The existing research studies can help in identifying three streams of studies (Cheng et al., 2015). In the first stream, the practices related to the In PLC are introduced in the first stream. Several companies operating the manufacturing networks do exist. In the similar way, these companies have acquired experience on the coordination between plants. Through the experience, the companies have developed their own practices including methods, processes, and structured tools. Specific case studies have introduced these practices including (Cheng et al., 2016). In the second stream, the studies about the distribution of knowledge, production expertise, and innovation between the plants and in the learning, network are involved. It has been revealed 
by the review of studies on InPLC that there are various types of InPLC including transfer of knowledge, sharing of information, and diffusion of innovation. All these are supported by the adoption of technology and developing an infrastructure for the organization. For InPLC, there is need for development of a comprehensive performance network management system and joint decision making between the plants (Cheng et al., 2015). However, the previous research studies have given little information about the contributions made by InPLC to the operational performance of a plant in network. In reality, some existing researches have specifically in the third stream have used the measure of performance as constraint or objective in the mathematical model for analysing the flow of materials across the plants. However, the sharing of knowledge, information, and collaboration among the networked plants has not been used explicitly (Jabbarzadeh et al,2017). Alternatively, some studies in the initial two streams have tried to examine the association between InPLC and operational performance (Miltenburg, 2018). A positive relation has been suggested for the relation of InPLC and operational performance. These studies are not based on empirical investigation but case studies (Netland \& Aspelund, 2014). Moreover, the transfer of production experience, innovation, and knowledge is supported through InPLC. Therefore, plants are supported to improve the designing of their products and processes. This results in the cost reduction and quality improvement of the product. In the similar way, the mutual exchange of knowledge about the schedules, processes, products, and capabilities enable the firm to coordinate the capacity of production for improving the delivery performance and production flexibility. In this research, the relation between operational performance and InPLC has been examined. This has been hypothesized as below:

H1: The interplant coordination is in significant relationship with the operational performance.

H2: The interplant coordination is in significant relationship with the internal supply chain integration.

The current dimensions and definitions have characterized Supply Chain Integration (Khan \& Wisner, 2019). However, two key dimensions can be made for $\mathrm{SCl}$, which include external and internal integration (Gelhard \& Von Delft, 2016). The degree with which the intra-organizational behaviours, procedures, and practices are structured by a manufacturer is referred as internal integration in the existing research studies. The requirements of customers and interaction with suppliers are enabled through synchronization and the managing the processes (Ahi \& Searcy, 2015; Srinivasan \& Swink, 2018). The sharing of information between the cross-functional strategic cooperation, internal functions, and mutual working is involved in it. It has been emphasized by researchers that there is need for analysing the internal integration because of its importance in the process of SCl. The influence of internal integration of the external integration has been analysed by (Gelhard \& Von Delft ,2016) from the aspect of organizational capability. It was highlighted that the influence is created in the form of strategic cooperation, mutual working, and sharing of information. There is positive relation of internal integration with operational performance, when it is regarded as the concept of $\mathrm{SCl}$ (Gelhard \& Von Delft, 2016). The degree with which the external partners are combined for the structuring of internal practices, strategies, behaviours, and processes is referred as external integration (Ahi \& Searcy, 2015). Customer and supplier integration are also involved in it. The sharing of information and coordination with the important suppliers is involved in supplier integration, which gives insight for the capabilities, processes, and constraints of the suppliers. The manufacturing plants practice to become effective in designing product, processes, planning, forecasting, and managing transaction (Jermsittiparsert \& Rungsrisawat, 2019a, 2019b; Somjai \& Jermsittiparsert, 2019). Activities based on sharing of information and close collaboration with the key customers are involved in customer integration. These offer insight into the market opportunities and expectations. The manufacturing plants become able to have a better understanding about the preferences of customers and development of relationship with the customers. The significant of a close integrated association between the supplier chain partners and manufacturers have been recognized by the researcher Christopher (2016). The influence of external integration on operational performance has been examined by different researches (Srinivasan \& Swink, 2018). Concluding, the 
relevant literature has addressed $\mathrm{SCl}$ in terms of external and internal integration. However, the current studies have not focused on coordination between plants within the similar network. Further, the current studies based on $\mathrm{SCl}$ have somehow focused on the manufacturing plant rather than the networked plant. Suppliers are facilitated through supplier integration to anticipate and understand the needs of networked plants. The networked plants are supported by the processes, products, capabilities, and schedules for the production planning and on time delivery of products. In the similar way, opportunities are offered through customer integration for the improvement of demand information accuracy. This reduces the product design of networked plant and planning time of production, and inventory obsolescence (Cheng et al., 2016). This results in reduction of cost, creation of greater value, and inspection of damages in a quicker way. The following hypotheses have been proposed in this regard:

H3: The internal supply chain integration is in significant relationship with the external supply chain integration.

H4: The operational performance is in significant relationship with the external supply chain integration.

Moreover, with the changes in external environment, there is need for a networked plant to respond through selection, development, and implementation of strategic for alignment with the internal as well as external environment. The internal integration of the networked plant is built on the external integration. It has been indicated by some other studies that for external integration, there is need for internal integration (Gelhard \& Von Delft, 2016; Khan \& Wisner, 2019). The relation of external and internal integration has been supported through empirically (Gelhard \& Von Delft, 2016). Few research studies exist, which are based on exploring the relation between internal and external integration by incorporating performance. Moreover, there is need for investigating the effect of external integration on the relation of operational performance and internal integration as a mediator. Most of the literature based on SCl has analysed the influence of external integration on the relation of performance and internal integration as a moderator (Ataseven \& Nair, 2017).

This research gap has tried to be addressed through proposing the following research hypothesis:

It has been suggested by the stage theory of $\mathrm{SCl}$ that the low-level $\mathrm{SCl}$ is internal integration in which the internal functions are integrated. However, the higher level of $\mathrm{SCl}$ is external integration, in which the integration of supply chain partners is done (Gelhard \& Von Delft, 2016). The coordination of inter-plant can be regarded as a middle level integration. This is far above the internal integration. It does not focus on the single firm nor does it address the collaboration of inter-firm with the external partners (Cheng et al., 2015; Feranita et al, 2017). A continuum of integration is represented by inter-plant collaboration, internal integration, and external integration. Therefore, the InPLC can be linked with the external and internal integration. The existing research studies have not discussed much the association between these. An absorptive capability to acquire knowledge from the external partners is represented by the internal integration from the aspect of organizational capability (Basheer et al, 2019; Enkel et al, 2018). External coordination is represented by the coordination and communication in the organization. It is argued that when there is high integration level in a networked plant, it can achieve InPLC to higher extent. According to (Gelhard \& Von Delft ,2016), sharing of information and cross-functional collaboration can elaborate the influence created on InPLC by internal integration. Alternatively, cooperation is required by the InPLC in the networked plant between various functional departments. For instance, it is mandatory to create a close association between the sales/purchasing/logistics functions with the manufacturing segment (Porter, 2016). This can support the production allocation and product distribution among the plants in an optimized way (Porter, 2016). It is less certain that information can be shared by a networked plant with other plants in the area of information sharing unless it has a well-established capabilities and internal systems for integration of information and data across the functional departments of the organization. In explanation, when real time visibility of data operating, and inventory is not possessed by a plant. Such data cannot be shared with other 
plants in the network. A good enterprise resource planning system enables a plant to ensure transparency in its functions and data for controlling and planning. In case, it is not possessed by a plant, the shared information cannot be used by other plants in an efficient way. Therefore, the following hypothesis has been proposed.

H5: The interplant coordination is in significant relationship with the external supply chain integration.

Moreover, the hypothesis can be made (by combining $\mathrm{H} 1$ and $\mathrm{H} 5$ ) about the role of InPLC as a mediator in the relation of operational performance and internal integration of a networked plant. Plants become able to manage the flow of products through InPLC. Moreover, it gives opportunities to improve information accuracy about the processes, products, demands, and capabilities between the plants. The external integration can be supported by timely and accurate information. External relations and uncertainties should be absorbed internally in proper places of the organization (Lii \& Kuo, 2016). Response can be made by the plant through communication with other plants in the network in relation to the external environment i.e. customers and suppliers. This case applies when the plant is not able to produce a large volume, or it exceeds its products capacity. It has been mentioned in the introduction that this benefit can be achieved by managing different groups as a network (Hislop et al , 2018). Access is provided by the InPLC to the resources, capabilities, and knowledge of other plants. In other case, it can be costly to develop such capabilities individually. The higher the acquired knowledge, the higher is the chance of managing relation of a networked plant with the customers and suppliers. In doing this, the relationship commitment can be strengthened by a network plant. This is referred as the readiness to establish and maintain relation, which is long term with the customers and suppliers. Based on the cooperative and beneficial coordination between the plants, external integration is created. In this way, development of relation with the customers and suppliers through commitment makes it easier to achieve the set goals and align the processes (Ahi \& Searcy, 2015; Gelhard \& Von Delft, 2016). The segmentation approach proposed by (Rungtusanatham et al, 2014) has been used to combine the hypothesis 3 and hypothesis 7, which is about the role of external integration as a mediator in the relation of operational performance and InPLC of a networked plant. The following research hypothesis has been made in this regard:

H6: Internal integration mediates the relationship between interplant coordination and external integration. H7: operational performance mediates the relationship between interplant coordination and external integration.

\section{METHODOLOGY}

Data analysis was based on inferential and descriptive statistics. The use of SPSS 22.0 was made for descriptive analysis. It helps in understanding the demographic variables and profile of respondents. In order to get comprehension of the concept, the variability and central tendency of the data was shown in descriptive statistics. Moreover, PLS-SEM was used in Smart PLS 3.0 to perform the inferential analysis. For obtaining sufficient rate of response, several phone calls were made to the selected firms accompanied with the follow up visits. Consequently, nine public universities were targeted for the survey and the questionnaires received were 360 . The response rate was about $60 \%$. Almost nine questionnaires had missing values and excluded from the analysis. The response rate decreased to $58.50 \%$. As per the suggestion of Sekaran, the response rate can be considered sufficient. The researcher recommended that the response rate of 30 percent could be regarded as sufficient. SEM is recently being used greatly because of its ability to analyse the multivariate data in social and behavioural sciences. For this reason, its use has increased in the education studies. The relation between the latent and observed variables can be analysed simultaneously through use of SEM groups. The use of SEM is beneficial when the intentions, attitudes, perceptions, characteristics, and attributes linked with educational research cannot be observed directly. The factor analysis and linear 
regression analysis are involved in SEM. By using the framework of SEM, two approaches including PLSSEM and CB-SEM can be used for analysis. The most common method of analysis is CB-SEM. This is applied frequently in AMOS, LISREL, and MPLUS. Different procedures of estimation are applied in every type of SEM with different objectives and by using different assumptions of distribution. The approach was firstly developed by Wold and Lohmoeller. The purpose of the approach is to maximize the variable of dependent variable through use of OLS method of estimation.

\section{RESULTS}

Under structural equation modelling (SEM), there are two major approaches for model estimation, 1) variance-based SEM and 2) covariance-based SEM (CB-SEM). The present research employed Partial Least Square-Structural Equation Modelling (PLS-SEM), which is a variance-based SEM approach. In this approach, the obtained data is used for analysing the relationship among the path coefficients to minimize residual variance or error terms of the endogenous variables (Ahmadian \& Abdolmaleki, 2018; Hair et al, 2014). According to (Sun et al ,2019), PLS-SEM modelling estimates the theoretical model involved in the research through Smart PLS 3.1.2. For current research, the PLS-SEM was chosen as a statistical technique to analyse the data. PLS-SEM is preferred instead of CB-SEM approach due to a number of reasons: 1) it is a good technique for prediction and model development. 2) It is suitable even when the data normality assumption is not satisfied. 3) It is ideal for those models with multiple observed variables or indicators and complex models; 4) it gives useful results when the subject under consideration is new and requires newly developed measurement model (do Valle \& Assaker, 2016; Hair et al., 2014). PLS-SEM is a two-stage model assessment, namely measurement model and structural model. There are two further approaches i.e. formative measurements and reflective measurements which have been recognized to assess the validity and reliability of the measurement or outer models. Primarily, reflective measures were calculated through outer-loadings using application software PLS-3, these measures are reflected by arrows i.e. from variables towards indicators. However, measures with arrows pointing from indicators to constructs are referred as formative measures which are quantified in terms of their own outer weights. Table 4.16 shows that all indicators involved in this research are reflective in nature. Therefore, the reflective models for current research will be considered by examining internal consistency reliability, construct validity (such as, convergent validity and discriminant validity) and indicator reliability.

The term indicator reliability refers as the percentage of variance in indicator which is explained by latent construct. Its value ranges from $0-1$. The indicator reliability can be obtained by analysing each construct's outer loadings (Davcik \& Sharma, 2016; Hair et al., 2014). Thus, in case of standardization of latent variables and indicators, the indicator reliability becomes equal to squared indicator loadings. According to a rule of thumb, if the loadings of reflective indicators exhibit less than 0.40 value within a PLS model, then it should be excluded from the model (Davcik \& Sharma, 2016). Only five data items were eliminated, however, only three items exhibited less than 0.70 but greater than 0.60 value, therefore, these items were retained, following (Ahmadian \& Abdolmaleki ,2018) suggestion. 


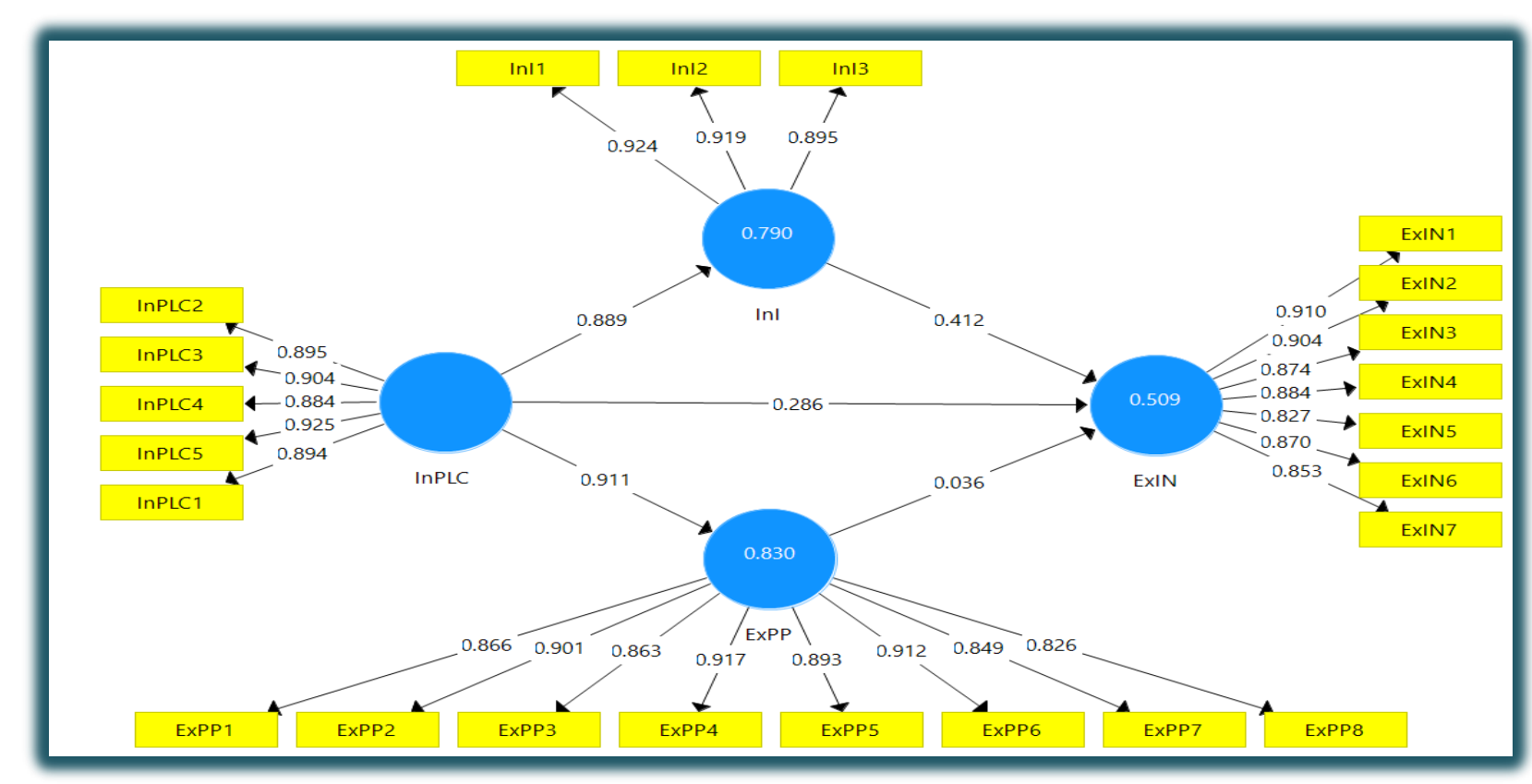

Figure 1. Measurement Model.

Table 1. Outer loading.

\begin{tabular}{|c|c|c|c|c|}
\hline & ExIN & ExPP & Inl & InPLC \\
\hline ExIN1 & 0.910 & & & \\
\hline ExIN2 & 0.904 & & & \\
\hline ExIN3 & 0.874 & & & \\
\hline ExIN4 & 0.884 & & & \\
\hline ExIN5 & 0.827 & & & \\
\hline ExIN6 & 0.870 & & & \\
\hline ExIN7 & 0.853 & & & \\
\hline ExPP1 & & 0.866 & & \\
\hline ExPP2 & & 0.901 & & \\
\hline ExPP3 & & 0.863 & & \\
\hline ExPP4 & & 0.917 & & \\
\hline ExPP5 & & 0.893 & & \\
\hline ExPP6 & & 0.912 & & \\
\hline ExPP7 & & 0.849 & & \\
\hline ExPP8 & & 0.826 & & \\
\hline Inl1 & & & 0.924 & \\
\hline In12 & & & 0.919 & \\
\hline $\ln 13$ & & & 0.895 & \\
\hline InPLC2 & & & & 0.895 \\
\hline InPLC3 & & & & 0.904 \\
\hline InPLC4 & & & & 0.884 \\
\hline InPLC5 & & & & 0.925 \\
\hline InPLC1 & & & & 0.894 \\
\hline
\end{tabular}


After checking uni-dimensionality of indicators, internal consistency was also examined. For this purpose, Composite reliability measure was employed in PLS-3 instead of using Cronbach's alpha (a). The composite reliability estimates the internal consistency reliability by observing the inter-correlations among the observed variables.

Tale 2. Reliability.

\begin{tabular}{|l|l|l|l|l|}
\hline & Cronbach's Alpha & rho_A & CR & (AVE) \\
\hline ExIN & 0.949 & 0.949 & 0.958 & 0.765 \\
\hline ExPP & 0.958 & 0.958 & 0.964 & 0.772 \\
\hline $\operatorname{lnl}$ & 0.899 & 0.901 & 0.937 & 0.833 \\
\hline $\ln P L C$ & 0.942 & 0.942 & 0.955 & 0.811 \\
\hline
\end{tabular}

It measures that to what level indicators of the construct converges and share greater variance proportion as compared to indicators of other constructs. Convergent validity measures that whether a particular item measures what it is supposed to measure. (Tzempelikos \& Gounaris ,2017) proposed average variance extracted as the criteria to assess convergent validity. AVE equals the construct's communality, which is described as the sum of indicators' square loadings of a construct, relative to total number of indicators. Therefore, when AVE $>0.50$ or above, it indicates that convergent validity is established, however, if AVE $<0.50$ it indicates no convergent validity since on average, the indicators variance cannot be explained by the construct, because of the presence of errors (do Valle \& Assaker, 2016; Hair et al., 2014). Thus, adequate convergent validity was achieved for the measures of this study, as AVE's for these measures came out as 0.598-0.953, which are above the minimum acceptable range that is 0.5 (Hair et al, 2017), other than for a policy measure which exhibited $A V E=1$, since it is a construct with only a single item.

Tale 3. Discriminant Validity.

\begin{tabular}{|l|l|l|l|l|}
\hline & ExIN & ExPP & Inl & InPLC \\
\hline ExIN & 0.875 & & & \\
\hline ExPP & 0.774 & 0.879 & & \\
\hline $\operatorname{lnl}$ & 0.700 & 0.715 & 0.893 & \\
\hline $\ln P L C$ & 0.786 & 0.711 & 0.889 & 0.901 \\
\hline
\end{tabular}

Discriminant validity refers to an extent that a particular construct's measures are different from other constructs' measures, in terms of empirical standards. Discriminant validity is achieved when a construct is distinct to other constructs in representing a particular phenomenon. In a reflective modelling, two methods are generally used to measure discriminant validity, 1) the cross-loadings of the indicators, which explains that for adequate discriminant validity, a particular constructs' indicator loadings must be greater than other construct's cross-loadings, in the underlying model. Therefore, if a construct's cross loading exceeds the construct's actual loading, then it indicates the violation of discriminant validity for a particular construct. 2) Using Fornell-Larcker criterion, which is a conservative discriminant validity measuring method, by comparing and examining each latent construct's square root AVE's with the correlations of latent variables for other latent construct. For a Fornell-Larcker discriminant validity, the square root AVE's must exceed its correlations with other constructs, in the absence of which the discriminant validity for reflective measurement cannot be achieved (do Valle \& Assaker, 2016; Hair et al., 2017). Table 4.11 shows that AVE's square root values (in bold) exceeded the correlations between the latent constructs, thereby showing adequate discriminant validity for this study. It has also been proposed that a construct's indicator loadings must exceed its cross loadings (Hair et al., 2017), therefore, Table 4.11 shows that all indicator loadings exhibited greater 
values in comparison to other reflective indicators involved in the measurement model. Thus, indicating that discriminant validity for measurement items has been achieved.

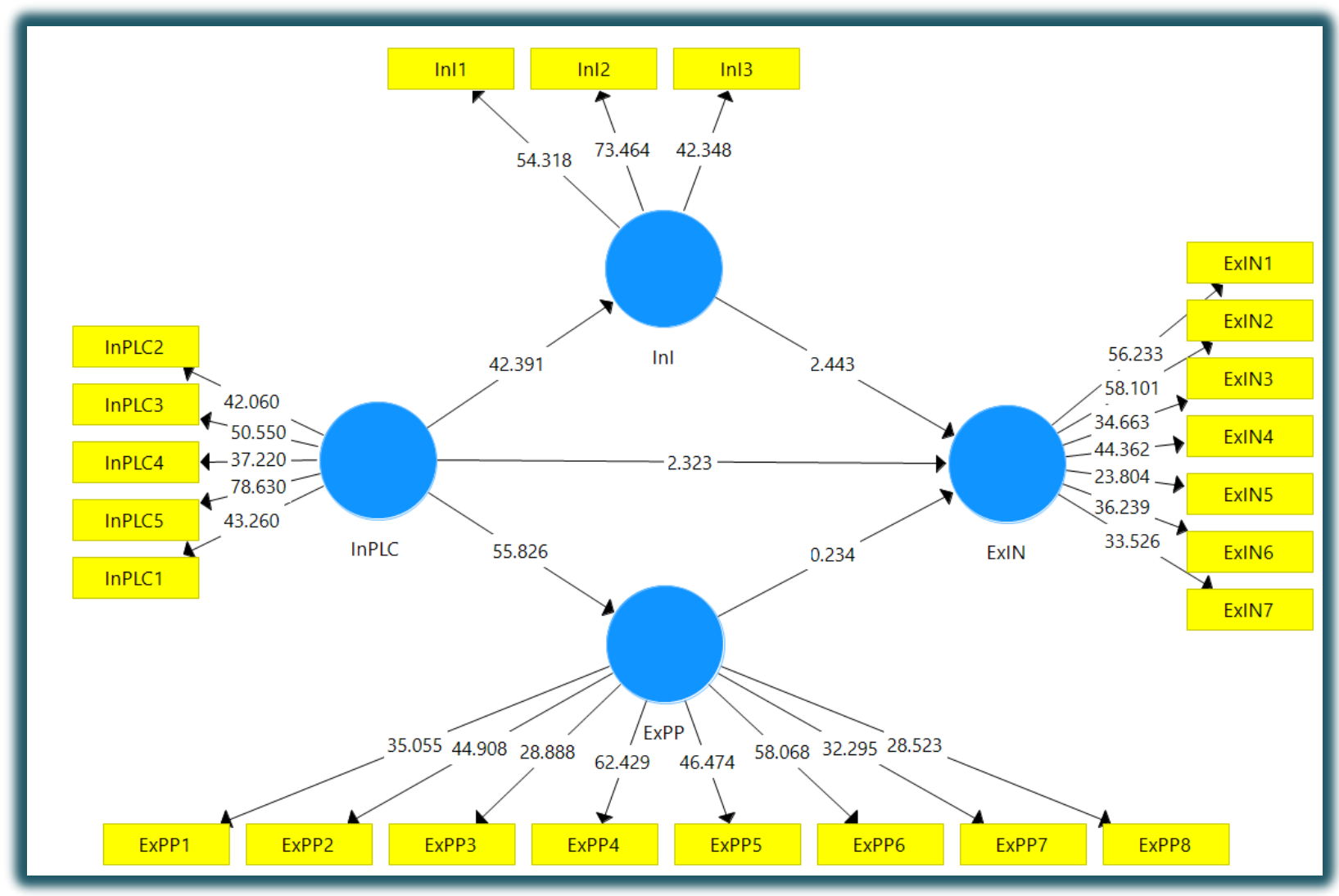

Figure 2. Structural Model.

(Hair et al, 2014) suggested that structural model shows the presence of dependent relationships that connects the variables within a hypothetical model. It shows the interrelationship between the models' constructs. Therefore, the structural relationship among decision making, job satisfaction, leadership style and leadership behaviour were tested by employing a structural model. Thus, in order to assess structural model in this study, measures like collinearity, relevance of structural relationships, significance of path coefficients, effect sizes, coefficient of determination, importance-performance matrix analysis (IPMA) and predictive relevance $\left(\mathrm{Q}^{2}\right)$ test were used. For generating t-statistics and standard errors, bootstrapping method was used, which is a non-parametric approach to check the precision of PLS estimates (Hair et al, 2016). (Henseler et al, 2015) suggested that bootstrapping procedure enables to examine statistical significance and indirect effects (if any) of the path coefficients.

Table 4. Direct relationship.

\begin{tabular}{|c|c|c|c|c|c|}
\hline & (0) & (M) & (STDEV) & (|O/STDEV $\mid)$ & $P$ Values \\
\hline ExPP -> ExIN & 0.036 & 0.030 & 0.155 & 0.234 & 0.407 \\
\hline Inl -> ExIN & 0.412 & 0.427 & 0.169 & 2.443 & 0.007 \\
\hline InPLC -> ExIN & 0.286 & 0.280 & 0.123 & 2.323 & 0.010 \\
\hline InPLC -> ExPP & 0.911 & 0.911 & 0.016 & 55.826 & 0.000 \\
\hline InPLC -> Inl & 0.889 & 0.889 & 0.021 & 42.391 & 0.000 \\
\hline
\end{tabular}


Table 4 and 5 represents all the results of this research. By combing these results, it can be said that direct paths from the InPLC and internal integration to the performance can be eliminated as depicted in Figure 2. The indices of the model fit are not changed by doing this. In the new setting, SEM path analysis has been run and indices have been obtained. These are similar to the previous indices, which confirm the results of all the hypotheses. The focus of this result is on the network plant. The research has analysed the relation between operational performance and $\mathrm{SCl}$ in the manufacturing network. The results of this study are similar to the previous researchers in some aspects and different in other aspects. The study found that there is a significant relation of external integration with a network plant's operational performance as hypothesized $(\mathrm{H} 3)$, which is in line with the results of previous studies (Panayides, 2017; Srinivasan \& Swink, 2018). The previous research studies have proved the significance of external integration. This has been supported by the study that operational performance can be improved through external integration. Internal integration has found to be insignificantly related with the network plant's operational performance. This finding is contradictory with the previous studies in which firm has been taken as a unit of analysis (Donckels \& Miettinen, 2019). However, it has been clearly revealed by this study that external integration is enabled through internal integration as shown in Table VI. The path of internal to the external integration is significant at level of $p$ 0.001. The results are similar to the findings of Gelhard and Von Delft (2016), who suggested an effective approach to be used by a networked firm to increase external integration through internal integration. It has been revealed further that internal integration can influence the operational performance even without creating a direct impact on the networked plant. This is done through external integration. Operational performance can be improved through internal integration efforts when the external integration is working. When there is no cooperation with the external partners, the firm cannot achieve better quality, flexibility, delivery, and services even it has high internal integration. Bad cooperation can offset the internal integration when there is no cooperation with the customers and suppliers (Cheng et al., 2016). Moreover, it has been shown by the previous studies that a positive relation exists between operational performance and InPLC based on case studies. It has not been found by our research theoretically. The result of first hypothesis reflects that operational performance and InPLC are not significantly related with each other. The result shows that the operational performance can be influenced through InPLC through external integration. Keeping in view the relation of internal integration with the operational performance, external integration mediates the influence of InPLC on operational performance (Anderson, 2017). This means that operation performance can be improved through making efforts on the inter-plant collaborations when the external integration exists.

Tale 5. Mediation.

\begin{tabular}{|l|l|l|l|l|l|}
\hline & $(\mathbf{O})$ & $(\mathbf{M})$ & (STDEV) & $($ O/STDEV $\mid)$ & P Values \\
\hline InPLC -> ExPP -> ExIN & 0.033 & 0.027 & 0.142 & 0.234 & 0.408 \\
\hline InPLC -> Inl -> ExIN & 0.366 & 0.380 & 0.151 & 2.422 & 0.008 \\
\hline
\end{tabular}

Measure of $R^{2}$ or coefficient of determination is a useful measure to assess if the exogenous variables can predict the variation in the endogenous variables. It is also used to analyse how well the exogenous variables predict the real data. It lies between $0-1$, where 1 represents that the regression prediction fits the data perfectly.

Tale 6. R-square.

\begin{tabular}{|l|l|}
\hline & R Square \\
\hline ExIN & 0.509 \\
\hline ExPP & 0.830 \\
\hline $\operatorname{lnl}$ & 0.790 \\
\hline
\end{tabular}


Other measure for estimating structural model is the predictive relevance of the model or $\mathrm{Q}^{2}$. This measure is used for measuring the reflective construct's relevance in a structural equation modelling (SEM) means that it shows a predictor variables' predictive relevance on the endogenous construct. Blindfolding procedure was used for calculating $Q^{2}$ value, by employing Smart PLS-3.

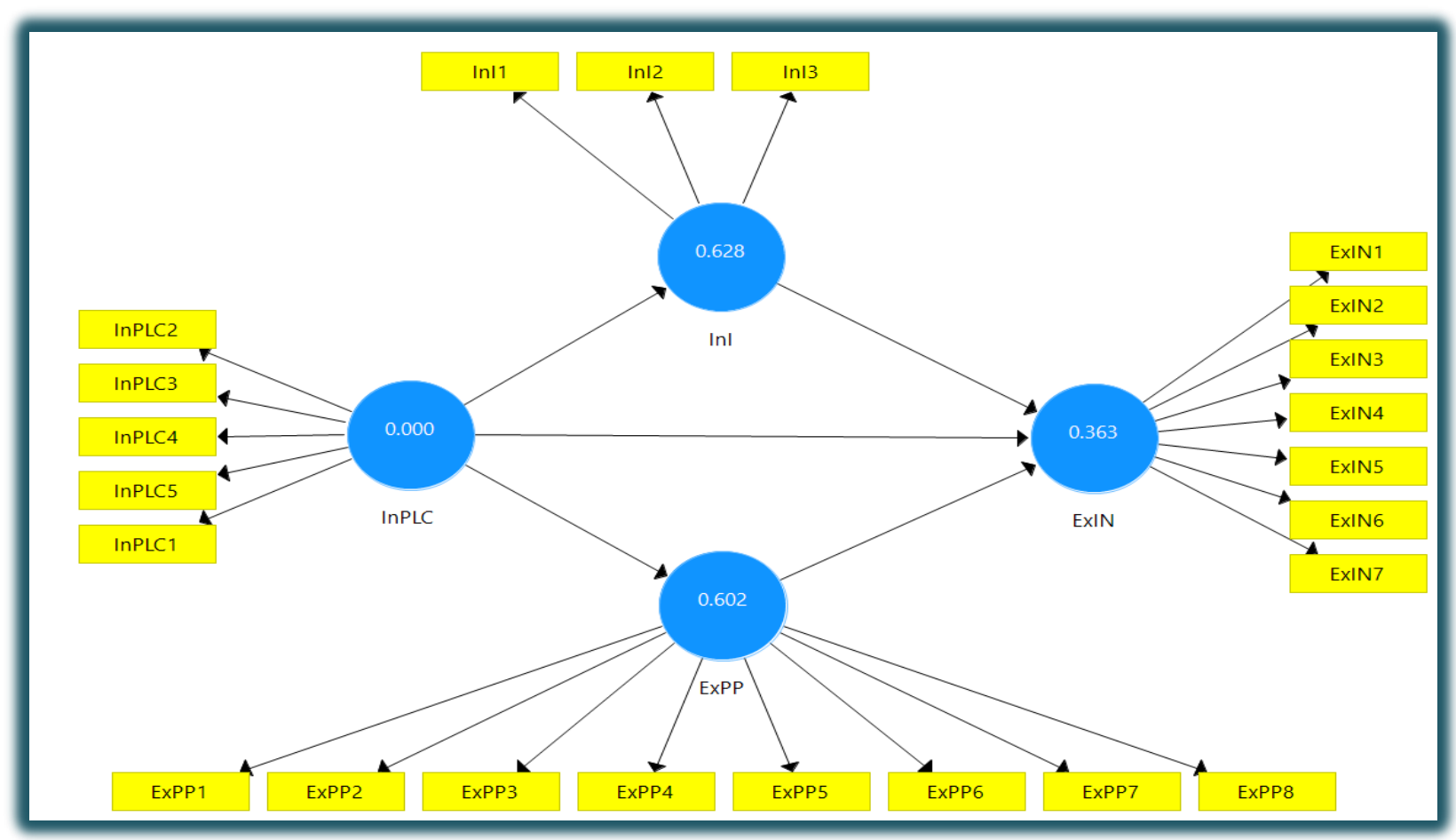

Figure 3. Q-square.

Therefore, this study adopted a cross-validated redundancy approach to obtain the constructs' predictive relevance. This approach is preferred as it includes predicted eliminated data, structural and path models' elements in its assessment (Hair et al., 2016).

Table 7. Blindfolding.

\begin{tabular}{|l|l|l|l|}
\hline & SSO & SSE & $\mathbf{Q}^{2}$ (=1-SSE/SSO) \\
\hline ExIN & $1,519.000$ & 967.161 & 0.363 \\
\hline ExPP & $1,736.000$ & 690.382 & 0.602 \\
\hline $\ln l$ & 651.000 & 242.089 & 0.628 \\
\hline $\ln P L C$ & $1,085.000$ & $1,085.000$ & \\
\hline
\end{tabular}

\section{CONCLUSION}

The focus of this research is on networked plant. The study has analysed the relation between $\mathrm{SCl}$, operational performance, and InPLC. The study has differentiated internal integration and InPLC. The extension of internal integration is internal-plant coordination as it involves eliminations of the functional silos in the internal integration are extended to span across the networked plants. This is distinct from the external integration as well. The external integration is based on individual firms and it does not deal in the firm's collaboration with external partners (Cheng et al., 2015). The research gaps identified in the field of SCl as 
well as InPLC have been tried to fill by this study. In the first part, the research contributes to the previous literature by analysing the relation of operational performance and $\mathrm{SCl}$ empirically. This has been done by giving evidence about the influence created on operational performance by external integration. Richness is added to the literature on $\mathrm{SCl}$. the understanding about the influence of external integration on the operational performance has been extended. The second contribution is made by the finding that external integration is enabled and supported through internal integration. In the manufacturing networked plant, the significance of internal integration is the formation of external integration is improved (Cheng et al., 2015). Preliminary evidence has been provided by this study on the influence of external integration as a mediator on the relation of operational performance and internal integration of a networked plant. The understanding about the InPLC and its association with operational performance and $\mathrm{SCl}$ has been supported in various aspects. The relation between SCI and InPLC has been tested, which is the first contribution, as it was not done previously. The positive impact of internal integration created on the InPLC has been evidenced by this study. This research has tested a novel theoretical model about the role of external integration as a mediator on the relation of interplant coordination and performance. The previous studies have been complimented by this research through analysing the way in which operational performance is influenced by InPLC in a networked plant (Acur et al, 2009). Further, a new causal path has been demonstrated by this research between InPLC, operational performance, and $\mathrm{SCl}$ through incorporating external integration and InPLC as mediators. The literature has been extended by revealing the network plant's operational performance can be improved through another path. This is through the coordination of external integration and inter-plant working in series. However, the first path should be given more credence. Lastly, by analysing the relation of SCI, InPLC, and operational performance, the significance of knowledge integration in the supply chain network and manufacturing network has been implied (Cheng et al, 2014).

\section{REFERENCES}

Acur, N., Voss, Chris, Stevenson, M., \& Spring, M. (2009). Supply chain flexibility: an inter-firm empirical study. International Journal of Operations \& Production Management. https://doi.org/10.1108/01443570910986238

Ahi, P., \& Searcy, C. (2015). An analysis of metrics used to measure performance in green and sustainable supply chains. Journal of Cleaner Production, 86, 360-377. https://doi.org/10.1016/j.jclepro.2014.08.005

Ahmadian, S., \& Abdolmaleki, S. (2018). Network typology and international opportunity recognition: moderating role of entrepreneurial orientation. Journal of Global Entrepreneurship Research, 8(1), 17. https://doi.org/10.1186/s40497-018-0104-8

Anderson, E. (2017). Extended value stream mapping: creating a supply chain view of phytosanitary compliance for export timber. Lincoln University.

Ataseven, C., \& Nair, A. (2017). Assessment of supply chain integration and performance relationships: A meta-analytic investigation of the literature. International Journal of Production Economics, 185, 252-265. https://doi.org/10.1016/j.ijpe.2017.01.007

Basheer, M., Siam, M., Awn, A., \& Hassan, S. (2019). Exploring the role of TQM and supply chain practices for firm supply performance in the presence of information technology capabilities and supply chain technology adoption: A case of textile firms in Pakistan. Uncertain Supply Chain Management, 7(2), 275-288. https://doi.org/10.5267/j.uscm.2018.9.001

Cheng, Y., Chaudhuri, A., \& Farooq, S. (2016). Interplant coordination, supply chain integration, and operational performance of a plant in a manufacturing network: a mediation analysis. Supply Chain Management: An International Journal, 21(5), 550-568. https://doi.org/10.1108/scm-10-2015-0391 
Cheng, Y., Farooq, S., \& Johansen, J. (2015). International manufacturing network: past, present, and future. International Journal of Operations \& Production Management, 35(3), 392-429. https://doi.org/10.1108/ijopm-03-2013-0146

Cheng, Y., \& Johansen, J. (2014). Operations network development: internationalisation and externalisation of value chain activities. Production Planning \& Control, 25(16), 1351-1369. https://doi.org/10.1080/09537287.2013.839064

Christopher, M. (2016). Logistics \& supply chain management: Pearson UK.

Davcik, N. S., \& Sharma, P. (2016). Marketing resources, performance, and competitive advantage: A review and future research directions. Journal of Business Research, 69(12), 5547-5552. https://doi.org/10.1016/i.jbusres.2016.04.169

do Valle, P. O., \& Assaker, G. (2016). Using partial least squares structural equation modeling in tourism research: A review of past research and recommendations for future applications. Journal of Travel Research, 55(6), 695-708. https://doi.org/10.1177/0047287515569779

Donckels, R., \& Miettinen, A. (2019). Entrepreneurship and SME research: on its way to the next millennium: Routledge.

Enkel, E., Groemminger, A., \& Heil, S. (2018). Managing technological distance in internal and external collaborations: absorptive capacity routines and social integration for innovation. The Journal of Technology Transfer, 43(5), 1257-1290. https://doi.org/10.1007/s10961-017-9557-0

Erfurth, T., \& Bendul, J. (2018). Integration of global manufacturing networks and supply chains: a cross case comparison of six global automotive manufacturers. International Journal of Production Research, 56(22), 7008-7030. https://doi.org/10.1080/00207543.2018.1424370

Feranita, F., Kotlar, J., \& De Massis, A. (2017). Collaborative innovation in family firms: Past research, current debates and agenda for future research. Journal of Family Business Strategy, 8(3), 137-156. https://doi.org/10.1016/i.jfbs.2017.07.001

Gelhard, C., \& Von Delft, S. (2016). The role of organizational capabilities in achieving superior sustainability performance. Journal of Business Research, 69(10), 4632-4642. https://doi.org/10.1016/j.jbusres.2016.03.053

Hair, Hult, G. T. M., Ringle, C., \& Sarstedt, M. (2016). A primer on partial least squares structural equation modeling (PLS-SEM): Sage publications. https://doi.org/10.3926/oss.37

Hair, Hult, G. T. M., Ringle, C. M., \& Thiele, K. O. (2017). Mirror, mirror on the wall: a comparative evaluation of composite-based structural equation modeling methods. Journal of the Academy of Marketing Science, 45(5), 616-632. https://doi.org/10.1007/s11747-017-0517-x

Hair, Sarstedt, M., \& Hopkins, L., Kuppelwieser, Volker. (2014). Partial least squares structural equation modeling (PLS-SEM) An emerging tool in business research. European Business Review, 26(2), 106-121. https://doi.org/10.1108/ebr-10-2013-0128

Henseler, J., Ringle, C. M., \& Sarstedt, M. (2015). A new criterion for assessing discriminant validity in variance-based structural equation modeling. Journal of the Academy of Marketing Science, 43(1), 115-135. https://doi.org/10.1007/s11747-014-0403-8

Hislop, D., Bosua, R., \& Helms, R. (2018). Knowledge management in organizations: A critical introduction: Oxford University Press.

Ibrahim, H. W., Zailani, S., \& Tan, K. C. (2015). A content analysis of global supply chain research. Benchmarking: An International Journal, 22(7), 1429-1462. https://doi.org/10.1108/bii-04-2013-0038

Jabbarzadeh, A., Fahimnia, B., \& Sheu, J.-B. (2017). An enhanced robustness approach for managing supply and demand uncertainties. International Journal of Production Economics, 183, 620-631. https://doi.org/10.1016/i.jije.2015.06.009 
Jermsittiparsert, K. \& Rungsrisawat, S. (2019a). Impact Strategic Sourcing, Supplier Innovativeness, and Information Sharing on Supply Chain Agility. International Journal of Innovation, Creativity and Change, 5(2), 397-415. https://doi.org/10.18510/hssr.2019.7418

Jermsittiparsert, K. \& Rungsrisawat, S. (2019b). The Supply Chain Management and Information Sharing As Antecedents of Operational Performance: A Case of SMEs. Humanities and Social Sciences Reviews, 7(2), 495-502. https://doi.org/10.18510/hssr.2019.7258

Khan, H., \& Wisner, J. D. (2019). Supply Chain Integration, Learning, and Agility: Effects on Performance. Journal of Operations and Supply Chain Management, 12(1), 14. https://doi.org/10.31387/oscm0360218

Lii, P., \& Kuo, F.-I. (2016). Innovation-oriented supply chain integration for combined competitiveness and firm performance. International Journal of Production Economics, 174, 142-155. https://doi.org/10.1016/j.ijpe.2016.01.018

Melander, L. (2018). Customer and supplier collaboration in green product innovation: External and internal capabilities. Business Strategy and the Environment, 27(6), 677-693. https://doi.org/10.1002/bse.2024

Miltenburg, J. (2018). Supply chains for iilicit products: Case study of the global opiate production $\begin{array}{lllll}\text { networks. Cogent Business \& } & 1423871 .\end{array}$ https://doi.org/10.1080/23311975.2018.1423871

Netland, T., \& Aspelund, A. (2014). Multi-plant improvement programmes: a literature review and research agenda. International Journal of Operations \& Production Management, 34(3), 390-418. https://doi.org/10.1108/ijopm-02-2012-0087

Olhager, J., Pashaei, S., \& Sternberg, H. (2015). Design of global production and distribution networks: A literature review and research agenda. International Journal of Physical Distribution \& Logistics Management, 45(1/2), 138-158. https://doi.org/10.1108/ijpdlm-05-2013-0131

Panayides, P. M. (2017). Global supply chain integration and competitiveness of port terminals Ports, cities, and global supply chains (pp. 43-56): Routledge.

Porter, M. (2016). Supply Chain Integration: A Correlational Study of Organizational Culture and Firm Performance. University of Phoenix.

Rungtusanatham, M., Miller, J., \& Boyer, K. (2014). Theorizing, testing, and concluding for mediation in SCM research: tutorial and procedural recommendations. Journal of Operations Management, 32(3), 99-113. https://doi.org/10.1016/i.jom.2014.01.002

Somjai, S. \& Jermsittiparsert, K. (2019). Mediating Impact of Information Sharing in the Relationship of Supply Chain Capabilities and Business Performance among the Firms of Thailand. International Journal of Supply Chain Management, 8(4), 357-368.

Srinivasan, R., \& Swink, M. (2018). An investigation of visibility and flexibility as complements to supply chain analytics: An organizational information processing theory perspective. Production and Operations Management, 27(10), 1849-1867. https://doi.org/10.1111/poms.12746

Sun, Y., Wang, N., \& Zhang, X. (2019). Bias effects, synergistic effects, and information contingency effects: Developing and testing an extended information adoption model in social Q\&A. Journal of the Association for Information Science and Technology. https://doi.org/10.1002/asi.24228

Tzempelikos, N., \& Gounaris, S. (2017). A conceptual and empirical examination of key account management orientation and its implications-the role of trust The Customer is NOT Always Right? Marketing Orientationsin a Dynamic Business World (pp. 673-681): Springer. https://doi.org/10.1007/978-3-319-50008-9_185 


\section{(c) (1) (9)}

This work is licensed under a Attribution-NonCommercial-NoDerivatives 4.0 International (CC BY-NC-ND 4.0). 